\title{
Human Resource Management Roles \& Skills Shortages in Malaysian Organisations
}

\author{
Noorziah Mohd Salleh, Abdul Kadir B. Hj. Rosline, Dg Kamisah Ag. Budin \\ Universiti Teknologi MARA (UiTM), Kota Kinabalu, Sabah, Malaysia \\ Email: noorziahs@yahoo.com
}

Received March 2015

\begin{abstract}
Human Resource Management (HRM) theorists report that four key roles of HRM are inter-related, namely strategic partner, change agent, employee champion, and administrative expert. Properly managed, these roles could result in efficiency, commitment, and competitive advantage in organisations. The roles may differ according to organisational objectives, industries and cultural values. Without adequate skilled, knowledgeable, qualified and experienced employees, on the other hand, organisational performance will be adversely affected. This research was carried out to investigate HRM roles and Malaysians skills shortages from the perspectives of a sample of HR managers in Malaysian organisations of different sizes and in various sectors. The findings revealed that most HR professionals played their roles as 'administrative experts' and less as 'strategic business partners' in large companies. This study also showed that there was a shortage of skills in the fields of accounting, information technology and human resource management in the Malaysian labour market.
\end{abstract}

\section{Keywords}

Human Resource Management, Skills Shortage, HR Capability/Competency, AHRI Model of Excellence

\section{Introduction}

Competent human resource managers play a very critical role in the organisations that they serve. According to (Ulrich et al., 1995) [1], the HR professional is a credible Activist, Culture and Change Steward, Talent Manager/Organisational Designer, Strategy Architect, Operational Executor and Business Ally. There are two categories of HR roles, viz. strategic and administrative roles. Strategic roles are defined as involvement in change management, contribution to policies and strategies and organisational strategic decision-making. Administrative roles, on the other hand, include managing day-to-day administration of staff activities (Truss and Gill, 2009) [2]. The HR professional may also take on the function of a business partner. Lawler (2005) defines the business partner role as one that involves the development of an effective HR system, implementation of business plans, talent management, problem solving, and the development of effective business system designs.

Researchers have conceptualized human resource management practice in several ways. It can be regarded as 
a system, a distinct practice, or a specific technique. Khan (2010) [3] proposes five key HRM practices, viz. training and development, recruitment and selection, compensation and reward, performance appraisal, and employee participation. Similarly, Schuler and Jackson (2007) [4] classify human resource management as initiatives in planning, staffing, assessment, compensation, training and development.

Malaysian organisations possibly face numerous difficulties and challenges in managing human resources. This might be due to the country's multiracial workforce, consisting of Malays, Chinese, Indians and other ethnic groups. Chinese earns highest salary than the Malays and Indians (MOHR-Minimum Wages, 2013). Having transformed itself in the 1970s from a producer of raw materials into an emerging multi-sector economy, Malaysia now depends largely on the manufacturing and services sectors to sustain its economy. The manufacturing sector provides jobs to nearly 40 per cent of the total workforce; workers in this sector received a recently increased minimum base wages between RM821.5 and RM1023 a month (MOHR-Minimum Wages, 2013). The sector generated an income of about RM55 billion a year, making it the second highest contributor to the country's domestic product (GDP) of USD 312.44 billion after the service sector (Tradingeconomics.com, 2015). The private sector provided the highest number of vacancies in 2010, i.e. 598,890 or 37 per cent of the total number of industrial vacancies in Malaysia (Labour \& Human Resources Statistics, 2012, pp. 8-12). Currently, the government aims to transform Malaysia into a high-income, fully developed nation by 2020 (Vision 2020). The private sector is therefore expected to play a pivotal role in helping the nation achieve this goal.

According to the Malaysian Labour and Employment statistics (2013), about 13,544,400 Malaysians were employed and the unemployment rate was 3 per cent (397,200 people). The statistics showed 35 per cent of the total labour supply had low qualifications. Only 25.1 per cent of the total labour supply had a bachelor's degree, or higher qualifications.Those who had non-technical skill certification qualification represented 5.2 per cent of the workforce. According to the Grant Thornton International Business Report (2013), about 62 per cent of companies in Malaysia found it difficult to source skilled workers. The survey also revealed that in the Asean region, the shortage of specific or technical skills was the most significant impediment for businesses. This was especially the case in Vietnam (affecting 86 per cent of businesses), followed by the Philippines (76 per cent) Malaysia (68 per cent), and Singapore (66 per cent). While the Malaysian government envisages achieving a high-income status, the challenges would be enormous in the absence of a highly skilled workforce. Malaysians need to develop and acquire relevant skills that can fulfill the immediate needs of the industry. Towards this end, the government offered 130,241 training places and financial assistance to the manufactuirng sector in 2012 (Labour and Human Resources Statistics, 2012, p. 45).

Within the above context, this research was carried out to explore the current Malaysian HR professional roles and employees' skills shortages in the country. It utilized an HRM Competency Framework (see Diagram 1 below) designed by the Australian Human Resources Institute (AHRI) and Ulrich and Brockbank.

\section{Literature Review}

\subsection{Skill Shortages}

In Malaysia, about 400,000 secondary school pupils take the national examination called Sijil Pelajaran Malaysia (SPM) each year just before they leave school. Candidates who pass this examination may enrol in a university, college or technical institution before entering the workforce. Although more than one million vacancies were recorded in 2012, this means more than 360 thousand people were unemployed during that year although jobs were readily available. According to Chook Yuh Yng, the country manager of JobStreet.com , an on-line recruitment website, many skilled Malaysian professionals seek better job offers overseas. Migration and seeking a better quality of life were as the main reasons for the brain drain in Malaysia (Malaysia \& Malaysia, 2014). Thus, as it is very difficult to to find suitably qualified Malaysians to fill positions in their company, many companies have no option but to resort to recruiting expatriates with the requisite skills and qualifications.

In addition, employable graduates are expected to possess the following competencies: (a) cognitive competencies such as skills in problem solving, critical thinking, formulating questions, searching for relevant information, making informed judgements, efficient use of information, conducting observations, investigations, inventing and creating new things, analysing data, presenting data communicatively, oral and written expression; (b) meta-cognitive competencies such as self-reflection or self-evaluation; (c) social competencies such as leading discussions and conversations, persuading, cooperating, working in groups; (d) affective dispositions 


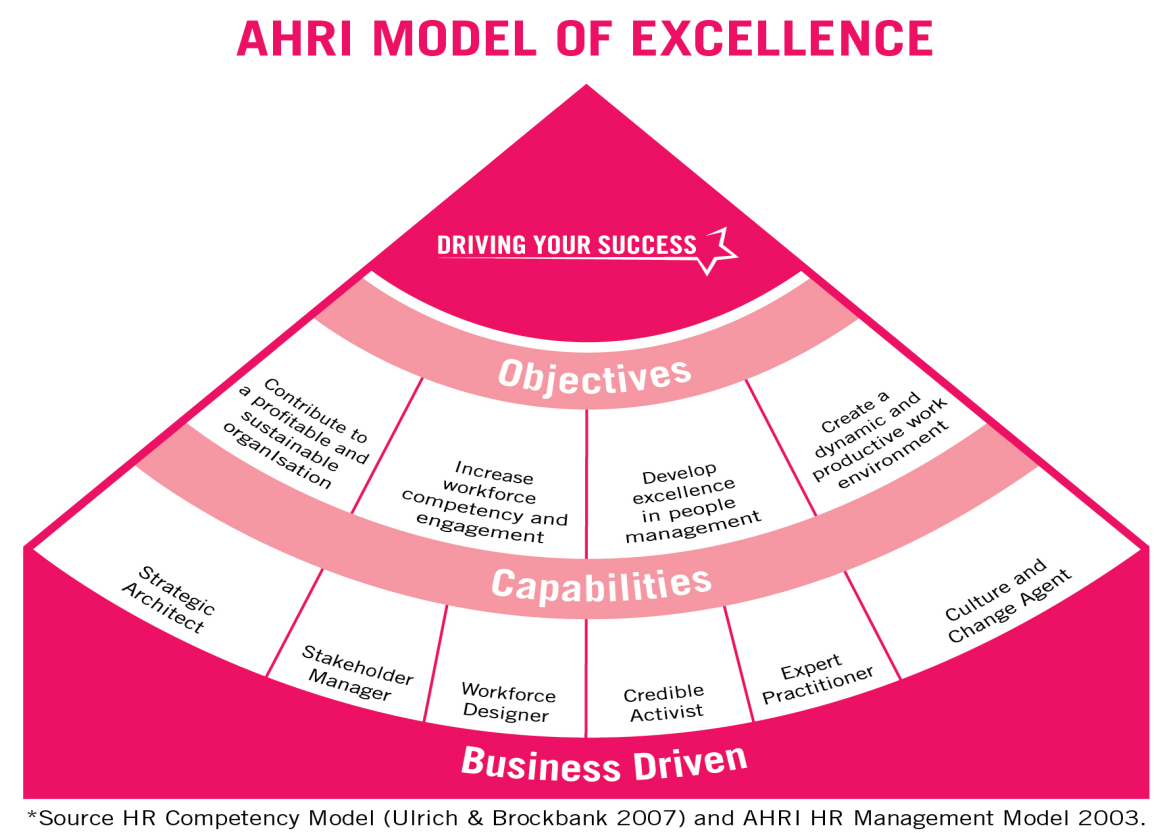

Diagram 1. Ahri model of excellence.

such as perseverance, internal motivation, initiative, responsibility, self-efficacy, independence, and flexibility (Birenbaum, 1996-cited in Tait and Godfrey, 1999, p. 246). Employable graduates need the services of HR managers who are responsible for attracting, retaining and managing the selected skilled employees and to further care for their wellbeing. To function effectively, therefore, HR managers and employees need to implement people strategy well.

\subsection{Malaysian HRM Roles}

To accelerate Malaysia's economic development, it is crucial for organisations to keep pace with rapid changes taking place in the global economic arena. As such, Malaysians need to constantly hone their skills and enhance their abilities to become a top class workforce on par with global standards (Ahmad Saufi, 2008) [5].

Malaysian organisations can be categorised as public or private, with the latter including multinational corporations (MNCs). Both the public and private sectors apply traditional human resource management that focuses mainly on recruitment, compensation, benefits, training, and performance appraisal. In 2002, the Malaysian public service sector implemented competencies-based human resource practices to improve the level of service quality (Azmi, 2010) [6]. For MNCs, three strategies are utilised in managing their human capital, viz. deployment workers or positioning them, global knowledge dissemination, and human capital development on a global basis. After the most productive workers have been identified, they are provided with training to enhance their skills and abilities (Ahmad Saufi, 2008) [5]. Thus, Malaysian organisations have moved a step ahead in improving its HRM.

Nevertheless, the problem of skills shortage and the diversification of human resource management roles cannot be adequately addressed without a proper understanding of its root causes. To ensure that skilled Malaysian workers do not migrate, Malaysia may need to increase salaries to compete with job offers from abroad. It may also need to raise its benchmark for human capital management roles in order to ensure better management of human resources. A model introduced by the Australian Human Resources Institute (AHRI) and the University of Michigan has been used to identify roles of HRM in Malaysia. This is the "Model of Excellence" promulgated by Prof. Dave Ulrich and Wayne Brockbank in 2003 (Ulrich et al., 2013) [7].

In this model, HRM comprises a number of interrelated objectives and competencies that are combined to drive business performance. HRM competencies components are business-driven and require the HR manager to play various roles such as being the strategic architect, stakeholder architect, stakeholder manager, workforce designer, credible activist, expert practitioner, and culture and change agent. The components of the model were used as the basis for this survey. Firstly, business driven is defined as a model that aligns people management 
strategies with business objectives and the external environment; secondly, the strategic architect sets and manages HR visions for the organisation; thirdly, the stakeholder manager identifies and responds to the stakeholder's demands and manages relationships; fourthly, the workforce designer builds organisational capabilities through high performing employees; fifthly, the credible activist exercises influence and provides advice for HR to achieve business objectives; sixthly, the expert practitioner applies expert HR knowledge to deliver value to the business; and finally, the culture and change agent facilitates change in response to internal and external operating environments. The capability components are underpinned by four HR objectives, viz. contribution to a profitable and sustainable organisation, increased workforce competency and engagement, development of excellence in people management, and the creation of a dynamic and productive work environment.

\section{Research Objectives}

The objectives of this research were to address the perceptions of HR managers on the skills shortages in Malaysia in a variety of organisational types and sizes, and to examine the roles of human resource measured in terms of administrative, functional and strategic business partner roles. This research aimed to add to earlier, more general research on these factors, and to suggest directions for future research. The specific research questions were:

i) What are the professional roles of HR personnel?

ii) What work skills is Malaysia short of?

\section{Significance of Research}

It is crucial to identify the type of skill shortages in Malaysia so that the problem can be appropriately addressed. In 2012, there were 1,619,473 vacancies. However, the number of available job seekers was only 475,275, making the ratio of vacancies to available workers 1:0.1. Interestingly, only 11,122 placements were made (Labour and Human Resources Statistics, 2012; p. 14). As such, it is important to investigate why it was not possible to fill the vacancies. It can be assumed that the vacant posts required people with specific skills but many job applicants did not fit the bill. As such, the type of skills shortages in the Malaysian job market needs to be identified.

It is also important to re-examine the roles of HR professionals who are generally known for creating organisational value through human capital. Therefore, the roles being played of Malaysian HR professionals need to be studied. Furthermore, to date, only minimal research evidence is present across the industry sectors in Malaysia.

\section{Methodology}

A survey was conducted to gather information concerning organisational details, respondent details and the Malaysians skills shortages from HR professional managers' perspectives in various types of organisations. Questionnaires were distributed to 500 private and government offices randomly selected from a broad crosssection of organisations, mainly those in Sabah. The target respondents were managers/practitioners who worked in Malaysian organisations. The survey questionnaire consisted of three sections: i) respondent and organisational details, ii) HRM department information, and iii) functions and competencies. The questionnaires were distributed from July to September 2014. A total of 416 useable responses were received and analysed using the SPSS statistical package.

\section{Research Findings}

Based on the useable completed questionnaires, the majority of respondents were from government departments or agencies (60.7\%), with significant representation from local private organisations (35.2\%) and a reduced number of respondents from international enterprises (3.2\%). A large number of the respondents worked in medium size businesses (47.5\%) or small organisations (20.5\%), whether in government or private sectors, with fewer $(18.3 \%)$ in large organisations. These organisations were defined by the number of the employees. The headquarters of the organisations were largely based in Malaysia (98.2\%), with a small percentage (1.8\%) in Singapore.

While most respondents were employed in education and training (16\%), finance and insurance (13.2\%), ad- 
ministration and support (12.3\%), agriculture, forestry and fishing (9.1\%), a wide spread of other sectors were represented as well. Similarly, there was a broad range of managerial positions, including human resource managers (42.9\%), middle and senior managers (26\%) and HR team leaders (8.7\%). Most of these were classified as middle to senior managers, many of whom had either a Bachelor's degree (41.6\%) or Master's degree (5\%) qualifications. Many respondents (42.1\%) did not have formal HRM-related certification. Of the respondents that possessed HRM-related qualifications, 11.4\% had HRM degrees while $7.3 \%$ held general business degrees with HRM subjects.

\section{Key HRM Roles and Competencies}

\section{Research Findings}

With respect to the three key HRM roles discussed earlier in this paper, clearly, the majority of the respondents in this study (Table 1) were of the view that that the HRM professionals in their organisations had adopted the "administrative expert" role (51.1\%) rather than the role of either a "strategic business partner" (33\%) or a "functional HRM specialist" (47\%). Table 1 shows that the "administrative expert" role was most evident in government departments and agencies, followed by "functional HRM specialist" and "strategic business partner" role. There was a similar pattern in private businesses, suggesting that the "administrative expert" role was perceived as the key role of Malaysian HR managers. The roles of HRM as strategic business partner and functional HRM specialist were also similarly rated.

Cross-tabulation analyses were further undertaken, with respect to the associations between organisational type/company size and specific HRM competencfies. With regard to the analysis between company size and key role of the HR department, most HR professionals in Malaysia were perceived as "administrative expert" and less "strategic business partner" in large companies. However, there was a tendency for the roles to change according to the size of the organisation. Thus, in smaller organisations, more HR professionals were involved in functional HRM specialist roles. In medium-sized organisations, the role of HR professionals as an administrative expert was perceived to be more evident.

Table 2 shows that it was most difficult to attract accountants (24 responses from 416 respondents). IT specialists were also difficult to hire (17 responses). HR professionals (16 responses) were ranked the third most difficult professionals to attract. The post which was considered as the least difficult to fill was that of the agricultural officer (2 responses).

Among the problems identified, the most common was the inability to offer attractive salary (19 responses), followed by industry competition (12 responses), and lack of career advancement opportunities (11 responses) (Table 3).

The skill that needed to be improved most was communication (44 responses), followed closely by problem solving/critical thinking (43 responses). Decision-making skills ranked third (38 responses). Based on the scope of this study, the skills that needed improvement in Malaysian organisations were generally cognitive skill/ competency and social competency (Table 4).

\section{Discussion and Conclusion}

The survey canvassed the views of a sample of respondents from companies and institutions comprising various organisational types concerning the roles of the HRM in their organisations as well as skills shortage. Feedback was gathered from managers from government departments and agencies, local private companies and interna-

Table 1. Key HRM role by ownership type.

\begin{tabular}{|c|c|c|c|c|c|}
\hline & & \multicolumn{3}{|c|}{ Key role of HRM department } & \multirow[b]{2}{*}{ Total } \\
\hline & & $\begin{array}{l}\text { Strategic business } \\
\text { partner }\end{array}$ & $\begin{array}{l}\text { Strategic/Functional } \\
\text { HRM specialist }\end{array}$ & $\begin{array}{l}\text { Administrative } \\
\text { expert }\end{array}$ & \\
\hline & Government & 33 & 47 & 51 & 131 \\
\hline \multirow[t]{3}{*}{ Ownership } & Private business & 21 & 20 & 35 & 76 \\
\hline & International company & 1 & 3 & 3 & 7 \\
\hline & Total & 55 & 70 & 89 & 214 \\
\hline
\end{tabular}


Table 2. Professions which have difficulty attracting suitably qualified applicants.

\begin{tabular}{ccc}
\hline & Frequency & Percent \\
\hline Not Relevant & 469 & 79.1 \\
Engineers & 11 & 1.9 \\
Managers & 14 & 2.4 \\
Accountants & 24 & 4.0 \\
Nurses & 6 & 1.0 \\
Doctors & 5 & 0.8 \\
IT Specialists & 17 & 2.9 \\
Marketing Specialists & 12 & 2.0 \\
HR professionals & 16 & 2.7 \\
Interpreters & 7 & 1.2 \\
Safety officers & 10 & 1.7 \\
Agricultural officers & 2 & 0.3 \\
Total & 593 & 100.0 \\
\hline
\end{tabular}

Table 3. Identified reasons for problems in hiring.

\begin{tabular}{ccc}
\hline & Frequency & Percent \\
\hline Not Relevant & 510 & 86.0 \\
Lack of sufficient qualified university graduates & 8 & 1.3 \\
Industry competition & 12 & 2.0 \\
Inability to offer attractive salary & 19 & 3.2 \\
Inability to provide attractive employee benefits & 10 & 1.7 \\
Unattractive location & 9 & 1.5 \\
Lack of career advancement opportunities & 11 & 1.9 \\
Organisation's reputation/image & 6 & 1.0 \\
Lazy & 1 & 0.2 \\
Current government policy to reduce recruitment & 1 & 0.2 \\
Inexperienced candidates/ applicants & 3 & 0.5 \\
Employees are determined by JPA & 1 & 0.2 \\
Difficulty or delay in securing approval from MOF & 1 & 0.2 \\
Lack of good talent & 1 & 0.2
\end{tabular}

tional companies, and small, medium and large organisations in various sectors.

Malaysian organisations generally expected their staff to possess at least a high school qualification (34.2\%); 16.9 per cent of the respondents said the minimum requirement for main positions was undergraduate qualification while 34.2 per cent said that a diploma qualification was required. The key HRM role in most organisations was that of an administrative expert role, concerned primarily with traditional roles; the functional HRM specialist was perceived as the second most important role. As such, it was concluded that Malaysian HR managers were moving towards a more contemporary professional status, but had yet to truly embrace its more strategic 
Table 4. Skills that need improvement among professional staff.

\begin{tabular}{ccc}
\hline & Frequency & Percent \\
Not relevant & 295 & 49.7 \\
Communication skills & 44 & 7.4 \\
Leading teams & 33 & 5.6 \\
Problem solving/critical thinking & 43 & 7.3 \\
Technical skills related to the professional field & 34 & 5.7 \\
Capacity to support \& develop employees & 27 & 4.6 \\
Recognizing good (\& bad) performance & 16 & 2.7 \\
Competence in planning and evaluating one's own work and that of others & 32 & 5.4 \\
Understanding how to work with people from different backgrounds and cultures. & 31 & 5.2 \\
Decision-making skills & 38 & 100.0 \\
\hline
\end{tabular}

potential, including a heightened role in human resource development. It further illustrated that the stages of HRM role development in Malaysia differed between sectors, ownership types and organisational size.

In terms of the skills shortages within the scope of this research, it can be concluded that there was a shortage of skilled personnel in accountancy, information technology, and professional human resource management. The results were consistent with a survey conducted by JobStreet.com in 2013 that also showed skilled accountant was the most demanded. As a middle-income status country (ranked $45^{\text {th }}$ out of 72 countries with an average monthly salary of US\$962 per month (World, 2012) [8] moving towards high-salary status, Malaysia's future growth would be constrained by serious talent shortages. This problem was exacerbated by the low qualification of its workforce (with only 25 per cent possessing a bachelor's degree qualification), as well as brain drain and quality of life issues. This study revealed that whilst there were differences in the forms and applications between diverse ownership types, HR professionals believed that it was important for them to play the strategic business partner role in Malaysian organisations.

It might be useful for future research to include larger and more representative samples of managers from across Malaysia, perhaps comparing the perspectives of generalists with those of HRM specialists. However, the search for representative and reliable research samples is a difficult task in emerging nations such as Malaysia for a number of reasons, including the lack of support from organisations and unfamiliarity with such research methods. Case study analyses would yield valuable information regarding the local HRM profession and how it could help organisations improve their performance. For HRM professionals, this study would increase their awareness of the importance of matching competencies/skills with the expectations or demands of their organisations. This study also stressed the need to have a more qualified workforce so that Malaysia would have the expertise needed to help achieve its vision of a high-income nation by 2020. As the HRM profession plays a vital role in improving the company's performance, it is vital that the people involved acquire the necessary competencies to meet their organisational objectives.

\section{References}

[1] Ulrich, D., Brockbank, W., Yeung, A.K. and Lake, D.G. (1995) Human Resource Competencies: An Empirical Assessment. Human Resource Management, 34, 473-495. http://dx.doi.org/10.1002/hrm.3930340402

[2] Truss, C. and Gill, J. (2009) Managing the HR Function: The Role of Social Capital. Personnel Review, 38, $674-695$. http://dx.doi.org/10.1108/00483480910992274

[3] Khan, A.M. (2010) Effects of Human Resource Management Practices on Organizational Performance: An Empirical Study of Oil and Gas Industry in Pakistan. European Journal of Economics, Finance and Administrative Sciences, 24, 157-174.

[4] Schuler, R.S. and Jackson, S.E. (2007) Human Resource Management: A Reader. Blackwell Publishers, London. 
[5] Ahmad Saufi, R., Mansur, K., Saiman, S., Uruoka, F. and Kato, I. (2008) Human Capital In Malaysia: Current and Future Challenges. Universiti Malaysia Sabah, Kota KInabalu, Sabah.

[6] Azmi, I.A.G. (2010) Competency-Based Human Resource Practices in Malaysian Public Sector Organizations. African Journal of Business Management, 4, 235-241.

[7] Ulrich, D., Brockbank, W., Younger, J. and Ulrich, M. (2013) Global HR Competencies: Mastering Competitive Value from the Outside in. McGraw-Hill.

[8] World, A. (2012) Average Monthly Salary for 72 Countries in the World-1-Million-Dollar-Blog. http://1-million-dollar-blog.com/average-monthly-salary-for-72-countries-in-the-world/ 